Chronic Obstructive Pulmonary Diseases:

Journal of the COPD Foundation

\author{
Original Research
}

\title{
Comparing Patients with ZZ Versus SZ Alpha-1 Antitrypsin Deficiency: Findings from AlphaNet's Disease Management Program
}

Radmila Choate, $\mathrm{MPH}^{1}$ David M. Mannino, $\mathrm{MD}^{1}$ Kristen E. Holm, PhD, $\mathrm{MPH}^{2}$ Robert A. Sandhaus, MD, $\mathrm{PhD}^{3}$

\section{Abstract}

Background: The aim of this study was to examine differences in demographic, health, and behavioral characteristics in individuals with ZZ and SZ genotypes of alpha-1 antitrypsin deficiency (AATD) within AlphaNet's Disease Management and Prevention Program (ADMAPP).

Methods: Self-reported data from 3535 patients with AATD, including 3031 (85.7\%) patients with ZZ, ZNull, and NullNull genotypes (referred to here as ZZ), and 504 (14.3\%) with the SZ genotype were analyzed using t-tests, ANOVAs, and Chi-squared tests.

Results: The average age of the cohort was $56.3 \pm 10.6$ years. The majority of respondents were male ( $51.2 \%)$, white (98.2\%) and married (65.2\%). SZs reported having more frequent exacerbations $(p<0.001)$ and hospitalizations $(p=0.012)$ than ZZs. A higher proportion of SZs than ZZs had been diagnosed with high blood pressure, diabetes, congestive heart failure, and other comorbid conditions. SZs were more likely than ZZs to report "poor" health $(p=0.005)$. Over a third (38.4\%) of SZs do not exercise compared to $27.1 \%$ of ZZs $(p<0.001)$. A greater proportion of SZs compared to ZZs view themselves as being overweight $(p<0.001)$ or "out of shape" $(p=0.001)$. A higher proportion of SZs than ZZs reported any history of smoking and current smoking $(p<0.001)$.

Conclusions: In patients with AATD and lung disease participating in a disease management program, a higher proportion of SZs than ZZs report exacerbations, comorbidities, and overall poor health, as well as unhealthy behaviors such as lack of exercise and current smoking. Future work should consider the extent to which genotype-specific health promotion interventions would be useful.

Abbreviations: alpha-1 antitrypsin deficiency, AATD; AlphaNet's Disease Management and Prevention Program, ADMAPP; protease inhibitor, PI; negative binomial, NB; Charlson Comorbidity Index, CCI; zero-inflated negative binomial, ZINB; Big Fat Referene Guide, BFRG; Akike information criterion, AIC; incident rate ratio, IRR; confidence interval, CI; standard deviation, SD; gastroesophageal reflux disease, GERD

Funding Support: This study was funded by an unrestricted research grant from AlphaNet.

Date of Acceptance: July 16, 2018

Citation: Choate R, Mannino DM, Holm KE, Sandhaus RA. Comparing patients with ZZ versus SZ alpha-1 antitrypsin deficiency: findings from AlphaNet's disease management program. Chronic Obstr Pulm Dis. 2019;6(1):29-39. doi: https://doi.org/10.15326/ jcopdf.6.1.2018.0134

1 Department of Preventive Medicine and Environmental Health, University of Kentucky College of Public Health, Lexington

2 Division of Medical, Behavioral, and Community Health, National Jewish Health; Department of Community and Behavioral Health, University of Colorado Denver School of Public Health, Denver

3 Division of Pulmonary Sciences and Critical Care Medicine, National Jewish Health, University of Colorado Denver School of Medicine, Denver

\section{Keywords:}

alpha-1 antitrypsin deficiency; genotype; AlphaNet Disease Management and Prevention Program; ADMAPP; ZZ; SZ

This article has an online data supplement. 


\section{Address correspondence to:}

Radmila Choate, MPH

Department of Preventive Medicine and Environmental Health

University of Kentucky College of Public Health

111 Washington Avenue

Lexington, KY 40536

Phone: 859-218-2237

E-mail:radmila.choate@uky.edu

\section{Introduction}

Alpha- 1 antitrypsin deficiency (AATD) is an autosomal co-dominant disorder that results from mutations of the SERPINA 1 gene and typically is associated with the increased risk of early onset pulmonary emphysema ${ }^{1}$ in adults, liver disease in children as well as adults and, more rarely, necrotizing panniculitis. ${ }^{2}$

SERPINA 1 is considered a polymorphic gene. ${ }^{3}$ The most common mutations of the gene associated with AATD are the PiZ and PiS mutations, where Pi stands for "protease inhibitor." The PiM-allele represents the normal genotype. Homozygous PiZZ is the most commonly identified severely deficient genotype while the PiS-allele leads to a milder plasma deficiency of AAT. $^{3}$ Over 200 mutations of the gene have been discovered, with approximately one-third of these mutations leading to clinically significant deficiency. ${ }^{4}$ Serum levels of AAT between 85 and $215 \mathrm{mg} / \mathrm{dL}$ are considered normal, ${ }^{5}$ although normal ranges vary by laboratory. Individuals with a ZZ genotype rarely have levels above $57 \mathrm{mg} / \mathrm{dL}$, and levels below this value are presumed to provide inadequate lung protection. ${ }^{4}$

Both $\mathrm{Z}$ and $\mathrm{S}$ mutations are believed to have originated among populations of European (nonHispanic white) descent. ${ }^{6}$ The Z-gene is associated with the Scandinavian/Baltic region, ${ }^{7}$ and the S-gene is considered to derive from the Iberian peninsula. ${ }^{8}$ AATD can be found in all major racial subgroups in the world, although often at a very low frequency. ${ }^{9}$

Previous studies that compared clinical features of SZ and ZZ patients have found significantly fewer respiratory symptoms, less severe airflow obstruction, and fewer radiographic lung abnormalities in SZ patients. ${ }^{10}$ Similarly, a study using the Spanish AATD registry (REDAAT) determined that ZZs have greater lung function impairment than SZs. ${ }^{8}$ The results of a large study in the United Kingdom demonstrated similar disease progression between $\mathrm{SZs}$ and ZZs although SZs had better baseline characteristics. ${ }^{11}$ These findings were explained by the greater importance of AAT levels rather than genotype. ${ }^{11}$ Other studies have demonstrated a correlation of serum AAT levels with the severity of emphysema. ${ }^{12}$ Regardless of genotype, smoking is the major risk factor for development of lung disease in patients with AATD. ${ }^{13,14}$

It is important to know whether genotype is associated with health outcomes and health behaviors, in order to determine whether individuals with the SZ genotype have differing needs from ZZs with regard to health education and behavioral interventions such as smoking cessation. The primary aim of our study was to examine differences in demographic, health, and behavioral characteristics in individuals with $\mathrm{ZZ}$ and SZ genotypes among individuals who are participating in a disease management program designed for patients with AATD and lung disease.

\section{Materials and Methods}

Our study population consisted of members of AlphaNet, a not-for-profit health management organization that coordinates management and treatment of individuals with AATD and lung disease in the United States. ${ }^{15}$ Enrollment in the AlphaNet Disease Management and Prevention Program (ADMPP) is offered when an individual is prescribed plasma-derived, intravenous AAT for the treatment of lung disease due to AATD (augmentation therapy). Analyses were conducted on coded data collected by AlphaNet. The study was approved by the University of Kentucky Institutional Review Board.

The inclusion criteria were that the participants were members of AlphaNet and had either a ZZ, ZNull, NullNull (analyzed in combination with ZZ) or SZ genotype of AATD. The final sample included 3535 respondents (Figure 1). Of these, 3031 (85.7\%) were identified as ZZs. The ZZs can be broken down as follows: $\mathrm{ZZ} \mathrm{(} \mathrm{n}=2979,98.3 \%)$, ZNull ( $\mathrm{n}=38,1.2 \%)$, and NullNull ( $\mathrm{n}=14,0.5 \%)$. Our analyses compared baseline characteristics of AATD patients with the ZZ genotype to those with the SZ genotype. All data were collected using questionnaires administered via a telephone interview. 
Figure 1. Study Sample Flow Diagram

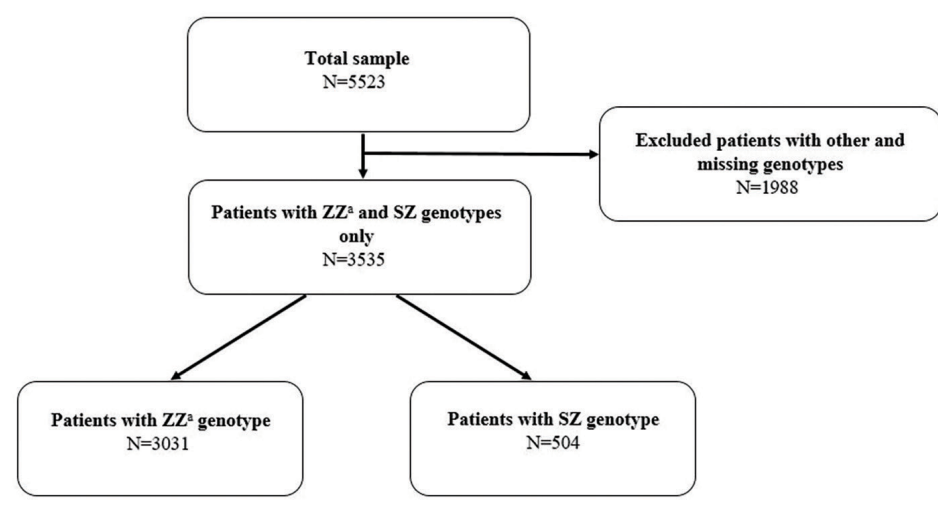

${ }^{\mathrm{a} C o m b i n a t i o n ~ o f ~ Z Z, ~ Z N u l l ~ a n d ~ N u l l N u l l ~ g e n o t y p e s ~}$

\section{Statistical Analyses}

Descriptive statistics were computed for baseline characteristics for the overall sample and stratified by genotype (ZZ versus SZ). The results for continuous variables were reported as mean $\pm S D$, and for categorical variables by frequencies and proportions. Values between the groups were compared using t-test/ ANOVA, and Chi-squared test respectively. Posthoc comparison of adjusted standardized residuals was used to determine the source of the statistically significant Chi-square for categorical variables. Negative binomial (NB) regression models were fit for frequency of exacerbations and visits to a primary care physician in the past year adjusting for age, sex, smoking status and Charlson Comorbidity Index (CCI). A zero-inflated negative binomial (ZINB) model was fit for frequency of hospitalizations adjusting for the same covariates. The significance level for all analyses was set at 0.05 . False discovery rate control was used to correct for multiple univariate testing. ${ }^{16}$ SAS 9.4 and SPSS version 22 were used for analyses.

\section{Results}

Table 1 describes the baseline demographic characteristics of the overall sample $(n=3535)$ and stratified by genotype: ZZ ( $\mathrm{n}=3031,85.7 \%$ ) and SZ $(n=504,14.3 \%)$. Average age of the study population was $56.3 \pm 10.6$ years. Patients with the ZZ genotype were slightly younger than SZs (55.9 years versus 58.6 years, $p<0.001$ ), and a greater proportion of ZZs were white (98.4\% versus $96.8 \%, p=0.012)$, and reported being married (66.1\% versus $59.3 \%, p=0.004)$. The majority of respondents were male (51.2\%) with no significant differences by genotype. Over $90 \%$ of all the respondents (92.7\%) were on augmentation therapy with a greater proportion of ZZs than SZs (93.5\% versus $87.1 \%, p<0.001$ ). The CCI score (which accounts for number and complexity of comorbidities) was significantly higher among SZs than ZZs $(p<0.0001) .^{17}$

A total of 3274 (97.6\%) patients reported ever having lung disease, with no significant difference between the genotypes. Emphysema/chronic bronchitis/COPD (96.8\%) and asthma (37.7\%) were the most frequent types of lung disease reported by the respondents.

Among those who reported ever having lung disease, significant differences were found in exacerbation frequency between ZZ and SZ patients $(p<0.001$, Table 2). Based on post-hoc analysis using standardized residuals, a significantly greater proportion of SZs than ZZs reported having monthly (20.2\% versus $13.9 \%)$ and quarterly (21.3\% versus $16.2 \%$ ) exacerbations, while ZZs reported more semi-annual exacerbations (13.9\% versus 9.6\%). SZs did not differ from ZZs with regard to the percentage who used oxygen regularly, number of hours oxygen was used per day, or coughing up sputum regularly.

The average number of visits to a primary care physician over the past year among all the respondents was $3.2 \pm 1.9$, and to a lung specialist was $2.9 \pm 1.7$. The mean number of hospitalizations was $0.7 \pm 1.3$. SZs reported more primary physician visits $(p<0.001)$, lung specialists visits $(p<0.001)$ and hospitalizations $(p=0.012)$ than ZZs.

Table 3 demonstrates the frequencies of the 10 most prevalent comorbidities within the overall study sample and stratified by genotype. The most frequent comorbidities were high blood pressure (40.3\%), gastroesophageal reflux (34.8\%), sinus disease (16.1\%), heart rhythm problems (12.9\%) and any tumor/cancer (11.9\%). Our study found that a statistically significant greater proportion of SZs in our cohort were diagnosed with the 6 most prevalent comorbidities. In addition, e-Table 1 in the online supplement contains information about all comorbidities for which AlphaNet collected data, several of which were also more prevalent among SZs.

Table 4 presents the results of self-reported health behaviors and fitness characteristics of ZZs and SZs. The majority of respondents reported having ever smoked (73.1\%), and a significantly greater 


\section{Table 1. Select Demographic and Clinical Characteristics of the Overall Sample and Stratified by Genotype}

\begin{tabular}{|c|c|c|c|c|c|}
\hline & $\begin{array}{c}\text { Data } \\
\text { Available }\end{array}$ & $\begin{array}{c}\text { Total } \\
(\mathrm{N}=3535)\end{array}$ & $\underset{(N=3031)}{Z}$ & $\begin{array}{c}S Z \\
(N=504)\end{array}$ & $P$-value \\
\hline Age, mean ( $S D)$ & 3535 & $56.3(10.6)$ & 55.9 (10.5) & $58.6(11.2)$ & $<.001$ \\
\hline Male & 3535 & $1808(51.2)$ & $1535(50.6)$ & $273(54.2)$ & .143 \\
\hline Race/ Ethnicity & 3475 & & & & .012 \\
\hline Non-Hispanic White ${ }^{a}$ & & $3412(98.2)$ & $2935(98.4)$ & 477 (96.8) & \\
\hline African-American & & $14(0.4)$ & $13(0.4)$ & $1(0.2)$ & \\
\hline Hispanic $^{a}$ & & $29(0.8)$ & $20(0.7)$ & $9(1.8)$ & \\
\hline Other $^{\mathrm{a}}$ & & $20(0.6)$ & $14(0.5)$ & $6(1.2)$ & \\
\hline Married & 3417 & $2227(65.2)$ & $1938(66.1)$ & 289 (59.3) & .004 \\
\hline Employed & 3135 & $1118(35.7)$ & $997(36.8)$ & $121(28.5)$ & .002 \\
\hline Augmentation Use & 2842 & $2634(92.7)$ & $2330(93.5)$ & $304(87.1)$ & $<.001$ \\
\hline History of Any Lung Disease & 3354 & $3274(97.6)$ & $2819(97.7)$ & $455(96.8)$ & .336 \\
\hline Emphysema/Chronic Bronchitis/COPD & 3204 & $3100(96.8)$ & $2681(96.9)$ & $419(95.7)$ & .165 \\
\hline Asthma & 3031 & $1144(37.7)$ & $993(37.8)$ & $151(37.2)$ & .806 \\
\hline Pneumonia & 2995 & $520(17.4)$ & $453(17.4)$ & $670(17.0)$ & .822 \\
\hline Bronchiectasis & 2999 & $292(9.7)$ & $263(10.1)$ & 29 (7.29) & .077 \\
\hline Charlson Comorbidity Index, mean (SD) & 3352 & $0.68(1.31)$ & $0.63(1.25)$ & $0.97(1.59)$ & $<.0001$ \\
\hline
\end{tabular}

Note: All statistics are reported as frequency (percentage) unless otherwise indicated.

${ }^{a}$ Denotes statistically significant difference based on post hoc analysis using standardized residuals

$\mathrm{SD}=$ standard deviation; $\mathrm{COPD}=$ chronic obstructive pulmonary disease

proportion of SZs than ZZs reported having ever smoked $(p<0.001)$. In addition, SZs are more likely to continue to smoke $(p<0.001)$, have been smoking longer $(p<0.001)$, and report smoking more packs per day $(p<0.001)$. Contrary to the findings for smoking, a higher proportion of ZZs report that they consume alcohol ( $p=.009)$, and ZZs consume more drinks per week on average than SZs ( $p=.030)$.

With respect to self-perceived health and fitness, a significantly greater proportion of SZs than ZZs view themselves as being overweight $(p<0.001)$, out of shape $(p=0.001)$ and in "poor health" $(p=0.005)$. More ZZs report that they exercise regularly compared to SZs, and $38.4 \%$ of $S Z s$ do not exercise at all compared to $27.1 \%$ of ZZs $(p<0.001)$.

The majority of patients reported that they follow the guidelines of ADMAPP (53.5\%), and a significantly greater proportion of ZZs report following the program compared to SZs $(p=0.026)$. Almost half of the participants (49.2\%) reported ever reading the Alpha-1 Big Fat Reference Guide (BFRG) ${ }^{18}$ with no difference by genotype.

Most patients reported being very comfortable with their knowledge about AATD (51.1\%). However, significant differences were found between the genotypes $(p<0.001)$. Specifically, a greater proportion of SZs, when compared to ZZs, reported being either "not comfortable" (9.8\% versus $4.0 \%)$ or "somewhat comfortable" (55.0\% versus $42.2 \%$ ) with knowledge about their condition.

Table 5 presents results of the adjusted NB and ZINB models. The criteria for assessing goodness of fit of each of the regression models showed adequate fit: deviance (scaled deviance) value/DF and Pearson ChiSquare (Scaled Pearson) value/DF were reasonably close to 1 (between 0.95 and 1.18) which indicates adequate fit of the models to the data. The selected regression models showed superior fit using Vuong test and Akike information criterion (AIC), corrected AIC and Baynesian information criterion when compared to other types of count models.

As demonstrated in Table 5, genotype was associated with the number of exacerbations and visits to a primary care physician after adjusting for age, gender, current smoking status, and CCI score. SZs had 1.21 times the rate of pulmonary exacerbations (incident rate ratio $[\mathrm{IRR}]=1.21,95 \%$ confidence interval [CI]: 1.05 1.40) and visits to a primary care physician (IRR $=1.21$, 95\%CI: 1.12-1.30) in the past year compared to ZZs. 


\section{Table 2. Exacerbations, Hospitalizations, Oxygen Use and Physician Visits in the Overall Sample and Stratified by Genotype}

\begin{tabular}{|c|c|c|c|c|c|}
\hline & $\begin{array}{c}\text { Data } \\
\text { Available }\end{array}$ & $\begin{array}{c}\text { Total } \\
(\mathrm{N}=3535)\end{array}$ & $\begin{array}{c}\mathrm{ZZ} \\
(\mathrm{N}=3031)\end{array}$ & $\begin{array}{c}S Z \\
(N=504)\end{array}$ & $P$-value \\
\hline $\begin{array}{l}\text { Exacerbation Frequency of Lung } \\
\text { Problems Over the Past Year }{ }^{a}\end{array}$ & 2903 & & & & $<.001$ \\
\hline Every Month ${ }^{b}$ & & $427(14.7)$ & $351(13.9)$ & $76(20.2)$ & \\
\hline Every 3 Months ${ }^{b}$ & & $489(16.8)$ & 409 (16.2) & $80(21.3)$ & \\
\hline Every 4 Months & & $285(9.8)$ & $252(10.0)$ & $33(8.8)$ & \\
\hline Every 6 Months ${ }^{b}$ & & $387(13.3)$ & $351(13.9)$ & $36(9.6)$ & \\
\hline Once & & $615(21.2)$ & $546(21.6)$ & $69(18.4)$ & \\
\hline Never & & $700(24.1)$ & $618(24.5)$ & $82(21.8)$ & \\
\hline \multicolumn{6}{|l|}{$\begin{array}{l}\text { Number of Exacerbations of Lung } \\
\text { Problems Over the Past Year }\end{array}$} \\
\hline Mean (SD) & 2903 & $3.2(3.9)$ & $3.1(3.8)$ & $3.9(4.3)$ & $<.001$ \\
\hline Regular Oxygen Use $^{a}$ & 2943 & $1515(51.5)$ & $1333(52.2)$ & $182(46.9)$ & .053 \\
\hline \multicolumn{6}{|l|}{$\begin{array}{l}\text { Regular Oxygen Use, }{ }^{\text {a }} \text { Average Hours } \\
\text { per Day }\end{array}$} \\
\hline Mean (SD) & 1470 & $15.5(7.9)$ & $15.6(7.9)$ & $15.3(7.9)$ & .740 \\
\hline 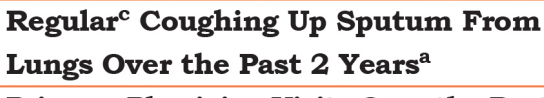 & 2863 & $1228(42.9)$ & $1056(42.3)$ & $172(46.9)$ & .099 \\
\hline \multicolumn{6}{|c|}{ Primary Physician Visits Over the Past Year } \\
\hline Mean (SD) & 3380 & $3.2(1.9)$ & $3.1(1.9)$ & $3.7(1.9)$ & $<.001$ \\
\hline \multicolumn{6}{|l|}{ Lung Specialist Visits Over the Past Year } \\
\hline Mean (SD) & 3382 & $2.9(1.7)$ & $2.9(1.7)$ & $3.2(1.7)$ & $<.001$ \\
\hline \multicolumn{6}{|l|}{ Hospitalizations Over the Past Year } \\
\hline Mean (SD) & 3362 & $0.7(1.3)$ & $0.6(1.2)$ & $0.8(1.3)$ & .012 \\
\hline
\end{tabular}

Note: All statistics are reported as frequency (percentage) unless otherwise indicated.

${ }^{a}$ Denotes frequency among patients with any type of lung disease

${ }^{b}$ Denotes statistically significant difference based on post hoc analysis using standardized residuals

${ }^{c}$ Denotes frequency of at least 3 months per year over the past 2 years

$\mathrm{SD}=$ standard deviation

\section{Discussion}

In 1996, Turino et al $^{10}$ described clinical features of a relatively small number of patients with the SZ genotype of AATD and AAT concentrations above or below $11 \mu \mathrm{M}(\sim 57 \mathrm{mg} / \mathrm{dL})$, including the effects of smoking on development of lung disease in SZs. More recent studies comparing characteristics of individuals with the ZZ and SZ genotypes were mainly carried out in Europe $8,11,19$ as the prevalence of S-allele is the highest in the general population of Spain and Portugal (17.3 and 13.8 per 1000, respectively). ${ }^{20}$ To our knowledge, this study is the first to focus on potential differences between SZs and ZZs in demographic, health, and behavioral characteristics among a large number of individuals ( $\mathrm{n}=3535)$ participating in a disease management program enrolling patients with AATD and lung disease.
Although any individual with AATD can enroll in AlphaNet's disease management program, the vast majority of individuals entered because of a prescription for augmentation therapy for lung disease due to AATD. Individuals not receiving augmentation therapy are moved to a different program within AlphaNet that focuses on risk reduction: Risk Evaluation to Ensure Continued Health. Thus, the population described here is greatly enriched for individuals with lung disease due to AATD. Since individuals with the SZ genotype are considerably less likely to develop lung disease than $\mathrm{ZZs},{ }^{10}$ many of the differences reported in this study may be reflective of the subpopulation of SZs with risk factor exposure sufficient to have led to clinically significant lung disease. Risk for development of lung disease is associated with the interaction between genetic factors and various environmental exposures such as smoking. ${ }^{13}$

Prior studies have noted higher mean smoking 


\section{Table 3. The Most Prevalent Comorbidities Reported by the Respondents in the Overall Sample and Stratified by Genotype}

\begin{tabular}{|c|c|c|c|c|}
\hline & $\begin{array}{c}\text { Total } \\
(\mathrm{N}=3535)\end{array}$ & $\underset{(\mathrm{N}=3031)}{\mathrm{ZZ}}$ & $\begin{array}{c}S Z \\
(N=504)\end{array}$ & $P$-value \\
\hline Data Available & $\mathrm{N}=3099$ & $\mathrm{~N}=2668$ & $\mathrm{~N}=431$ & \\
\hline High Blood Pressure & $1248(40.3)$ & $1024(38.4)$ & $224(52.0)$ & $<.001^{\mathrm{a}}$ \\
\hline Gastroesophageal Reflux (GERD, Heartburn) & $1077(34.8)$ & 903 (33.9) & $174(40.4)$ & $.008^{\mathrm{a}}$ \\
\hline Sinus Disease & 499 (16.1) & $411(15.4)$ & $88(20.4)$ & $.009^{\mathrm{a}}$ \\
\hline Heart Rhythm Problem & 399 (12.9) & $319(12.0)$ & $80(18.6)$ & $.001^{\mathrm{a}}$ \\
\hline Any Tumor or Cancer & 369 (11.9) & $299(11.2)$ & $70(16.2)$ & $.003^{\mathrm{a}}$ \\
\hline Diabetes & $268(8.7)$ & $195(7.3)$ & $73(17.0)$ & $<.001^{\mathrm{a}}$ \\
\hline Skin Problems (such as panniculitis) & $258(8.3)$ & $228(8.6)$ & $30(7.0)$ & .269 \\
\hline Pulmonary Hypertension & $204(6.6)$ & $169(6.3)$ & $35(8.1)$ & .165 \\
\hline Peripheral Vascular Disease & $199(6.4)$ & $169(6.3)$ & $30(7.0)$ & .623 \\
\hline Connective Tissue Disease & $192(6.2)$ & $160(6.0)$ & $32(7.4)$ & .254 \\
\hline
\end{tabular}

Note: All statistics are reported as frequency (percentage) unless otherwise indicated.

${ }^{a}$ Significant results after false discovery rate control

GERD=gastroesophageal reflux disease

consumption by SZs compared to ZZs. ${ }^{21}$ Our findings complement these observations by showing that when compared to ZZs, SZs had a significantly longer smoking history with a greater number of packs smoked per day. Further, the SZs in our sample were more likely to continue smoking after being diagnosed with lung disease. These results reflect the importance of emphasizing behavioral interventions and health education including smoking cessation, especially among SZs, as well as early diagnosis of AATD prior to the development of heavy smoking habits. ${ }^{21}$

Exacerbations commonly occur among patients with AATD-related lung disease ${ }^{22}$ and, in previous research, were demonstrated to be associated with a decline in lung function. ${ }^{22}$ In our sample, SZs reported more frequent exacerbations than ZZs, even after adjusting for age, sex, current smoking status and CCI score. Possible explanations include greater prior exposure to smoking, and lower adherence to healthy lifestyle recommendations, including adherence to AlphaNet's disease management program. However, lack of pulmonary function data limited our ability to compare lung disease severity between genotypes.

Previous research has demonstrated an association between AATD and certain comorbidities, such as ulcerative colitis and hypothyroidism ${ }^{23}$ among ZZs. Other studies demonstrated associations between $\mathrm{ZZ}$ and MZ genotypes of AATD and reduced blood pressure, as well as $\mathrm{MZ}$ and reduced risk of ischemic cerebrovascular and ischemic heart disease. ${ }^{24,25}$ Our results show a significantly higher prevalence of cardiovascular comorbidities, including hypertension, cerebrovascular disease, congestive heart failure, and arrhythmia among SZs compared with ZZs. The reasons for this association with SZ genotype are not well understood, nor sufficiently investigated previously. It should be noted that SZs in our cohort are slightly older than ZZs; also, the diagnosis of AATD may prompt a more thorough assessment for other health problems among SZs. Additionally, our findings of unhealthy lifestyle of the majority of SZs in our study population, may have contributed to the greater prevalence of cardiovascular comorbidities among patients with this genotype.

Previous research has explored the effects of genetic information on health behaviors of patients and their families. ${ }^{26-30}$ These studies have found inconsistent results with regard to the effect of genetic information on smoking cessation and motivation to improve diet and physical activity. Our study demonstrated that ZZs and SZs significantly differ in their perception of health and fitness as well as their health behaviors. A greater proportion of SZs viewed themselves as overweight, out of shape and in poor health, and they also exercise less and report a heavier and longer history of smoking compared with ZZs in our study. These findings may be explained by the perception that the SZ genotype presents a lower risk of the disease in view of the 


\section{Table 4. Self-Reported Health Behaviors and Fitness Characteristics in the Overall Sample and by Genotype}

\begin{tabular}{|c|c|c|c|c|c|}
\hline & $\begin{array}{c}\text { Data } \\
\text { Available }\end{array}$ & $\begin{array}{c}\text { Total } \\
(\mathrm{N}=3535)\end{array}$ & $\begin{array}{c}Z Z \\
(N=3031)\end{array}$ & $\begin{array}{c}S Z \\
(N=504)\end{array}$ & $P$-value \\
\hline Ever Smoking History & 3105 & $2270(73.1)$ & $1937(72.0)$ & $333(80.6)$ & $<.001$ \\
\hline Still Smoking & 2257 & $106(4.7)$ & $68(3.5)$ & $38(11.5)$ & $<.001$ \\
\hline Max Number of Packs/ Day Mean (SD) & 2197 & $1.4(0.8)$ & $1.4(0.8)$ & $1.7(0.9)$ & $<.001$ \\
\hline Years of Smoking Mean (SD) & 2162 & $19.9(9.9)$ & $18.4(8.7)$ & $28.5(11.9)$ & $<.001$ \\
\hline Consume Alcohol & 3027 & $1372(45.3)$ & 1216 (46.4) & $156(38.6)$ & .009 \\
\hline Number of Drinks/Week Mean (SD) & 1328 & $5.4(6.3)$ & $5.5(6.5)$ & $4.3(4.8)$ & .030 \\
\hline Do You Exercise & 3103 & & & & $<.001$ \\
\hline$N o^{a}$ & & $888(28.6)$ & $729(27.1)$ & 159 (38.4) & \\
\hline Irregularly & & $1071(34.5)$ & $945(35.1)$ & $126(30.4)$ & \\
\hline Regularly $^{a}$ & & $1144(36.9)$ & $1015(37.8)$ & $129(31.2)$ & \\
\hline Perception of Weight & 3077 & & & & $<.001$ \\
\hline Underweight & & 349 (11.3) & $299(11.2)$ & $50(12.2)$ & \\
\hline About Right ${ }^{a}$ & & $1249(40.6)$ & $1123(42.1)$ & $126(30.7)$ & \\
\hline Overweight ${ }^{a}$ & & $1479(48.1)$ & $1244(46.7)$ & $235(57.2)$ & \\
\hline Perception of Fitness & 3054 & & & & .001 \\
\hline Out of Shape ${ }^{a}$ & & $1396(45.7)$ & 1179 (44.5) & 217 (53.7) & \\
\hline Getting Fit & & $606(19.8)$ & $525(19.8)$ & $81(20.1)$ & \\
\hline Pretty Fit ${ }^{a}$ & & 957 (31.3) & $860(32.5)$ & $97(24.0)$ & \\
\hline Very Fit & & $95(3.1)$ & $86(3.3)$ & $9(2.2)$ & \\
\hline Perception of Health & 3069 & & & & .005 \\
\hline Poor ${ }^{a}$ & & $529(17.2)$ & $436(16.4)$ & $93(22.6)$ & \\
\hline Fair & & $1272(41.5)$ & $1112(41.8)$ & $160(38.9)$ & \\
\hline Good & & $1136(37.0)$ & 988 (37.2) & $148(36.0)$ & \\
\hline Excellent ${ }^{a}$ & & $132(4.3)$ & $122(4.6)$ & $10(2.4)$ & \\
\hline Follow ADMAPP & 2412 & 1291 (53.5) & $1154(54.4)$ & $137(47.4)$ & .026 \\
\hline Ever Read BFRG & 3027 & $1488(49.2)$ & 1300 (49.6) & $188(46.3)$ & 0.22 \\
\hline Comfortable with Alpha-1 Knowledge & 3438 & & & & $<.001$ \\
\hline $\mathrm{No}^{a}$ & & $167(4.9)$ & $119(4.0)$ & $48(9.8)$ & \\
\hline Somewhat ${ }^{a}$ & & $1513(44.0)$ & $1244(42.2)$ & $269(55.0)$ & \\
\hline Very $^{a}$ & & $1758(51.1)$ & $1586(53.8)$ & $172(35.2)$ & \\
\hline
\end{tabular}

Note: All statistics are reported as frequency (percentage) unless otherwise indicated.

${ }^{a}$ Denotes statistically significant difference based on post hoc analysis using standardized residuals

$\mathrm{SD}=$ standard deviation; $\mathrm{BFRG}=$ Big Fat Reference Guide; ADMAPP=Alphanet's Disease Management and Prevention Program

higher AAT levels in plasma. Our findings with regard to alcohol consumption suggest that, regardless of genotype, additional education about moderation of alcohol consumption should be considered due to the increased risk of liver disease among individuals with AATD.

ADMAPP is a vital part of AlphaNet's commitment to improve patients' health outcomes. ${ }^{15,31}$ Our study shows that a significantly lower proportion of SZs report following the guidelines of ADMAPP compared to ZZs. This lower adherence to the program may be due to the earlier mentioned concept of the low self- perceived seriousness of their condition. It should also be noted that SZs are less comfortable with the level of their knowledge about AATD compared to ZZs.

Understanding differences and similarities between various genotypes of AATD is of great importance from the public health perspective. Early knowledge and awareness of AATD allows for timely testing, smoking prevention and cessation, and initiation of augmentation therapy when indicated. ${ }^{32}$ 


\section{Table 5. Results of Adjusted ${ }^{\mathrm{a}}$ Analyses Comparing Patients with SZ versus ZZ Genotype}

\begin{tabular}{|c|c|c|c|c|}
\hline Outcome & $\begin{array}{c}\text { Parameter } \\
\text { Estimate }^{\mathrm{b}}(\mathrm{SE})\end{array}$ & $P$-value & $\begin{array}{l}\text { Rate } \\
\text { Ratio }\end{array}$ & $95 \% \mathrm{Cl}$ \\
\hline $\begin{array}{l}\text { Frequency of Pulmonary Exacerbations in the } \\
\text { Past Yearc }\end{array}$ & $0.20(0.07)$ & 0.0074 & 1.21 & $(1.05-1.40)$ \\
\hline $\begin{array}{l}\text { Frequency of Hospitalizations in the } \\
\text { Past Yeard }\end{array}$ & $0.21(0.11)$ & 0.0564 & 1.23 & $(0.99-1.52)$ \\
\hline $\begin{array}{l}\text { Frequency of Visits to a Primary Care physician } \\
\text { in the Past Year }\end{array}$ & $0.19(0.04)$ & $<.0001$ & 1.21 & $(1.12-1.30)$ \\
\hline
\end{tabular}

\footnotetext{
${ }^{\mathrm{a}}$ Adjusted for age, gender, current smoking status, and CCI score

${ }^{\mathrm{b}}$ Parameter Estimate (SE) for SZ genotype

${ }^{\mathrm{c}}$ Results of negative binomial regression

${ }^{\mathrm{d}}$ Results of zero-inflated negative binomial regression

$\mathrm{CI}=$ confidence interval
}

\section{Strengths and Limitations}

This is the first study to examine demographic, health, and behavioral factors in a large population of lungaffected individuals with AATD who are participating in a disease management program. Our results suggest that, among individuals with AATD who have developed lung disease, people with a less severe genotype who develop lung disease have worse health outcomes and health behaviors. Thus, the people who are less at risk (from a genetic standpoint) to develop lung disease may actually do worse once they have developed lung disease. While prevention efforts may need to be targeted to ZZs (since they are most at risk to develop disease) it is possible that disease management may be even more vital to SZs.

Several limitations must be acknowledged. First, a considerably larger fraction of ZZs develop lung disease compared with SZs. Since only patients with lung disease were invited to participate in ADMAPP, this may have introduced ascertainment bias into the study. Although, both SZs and ZZs were enrolled based on the presence of lung disease. This study provides no information about the comparative characteristics of SZs and ZZs without lung disease. Second, causality cannot be inferred due to the cross-sectional design of our study. Third, objective data were not available to provide more specifics on clinical phenotyping of lung disease, including CT findings and lung function measurements. Another limitation of our study is unavailability of the actual date of AATD diagnosis in most patients, which limits our ability to account for the length of time since diagnosis. The benefits of earlier age at diagnosis might be reflected in behavior modifications such as smoking cessation or improved exercise habits, which might contribute to better outcomes.

\section{Conclusion}

In summary, the results of this study document that ZZ and SZ patients in AlphaNet's disease management program differ with regard to health outcomes and health behaviors. Individuals with the SZ genotype have more comorbid health conditions and are less likely to engage in health-promoting behaviors such as exercise and smoking cessation. It appears that individuals with the more severely deficient ZZ genotype are more adherent to ADMAPP recommendations and maintain a healthier lifestyle than individuals with the less severely deficient SZ genotype. As such, improvements in education efforts may be especially beneficial for individuals with the SZ genotype who have lung disease, even though their underlying AATD is considered to be less severe.

\section{Acknowledgments}

Author contributions: Radmila Choate conducted the data analyses and drafted the manuscript. David M. Mannino and Kristen Holm have actively contributed to the data analysis and the manuscript preparation, Robert A. Sandhaus participated in the study design and contributed substantially to preparation of the manuscript. All authors read and approved the final manuscript. 


\section{Declaration of Interest}

David Mannino is a full-time employee of GlaxoSmithKline plc and owns stock of GlaxoSmithKline plc. Furthermore, he has received royalties from Up-to-Date, and has been compensated as a medical expert in legal cases. Robert Sandhaus has served on advisory boards and/or as a speaker for Grifols, CSL Behring, Shire, and AstraZeneca. He is on the board of directors of AlphaNet and the Alpha-1
Project, is on the Medical Advisory Committee of the COPD Foundation and serves as the Medical Director of AlphaNet. Kristen Holm has received consulting income from AlphaNet. Radmila Choate has received research support from AlphaNet. 


\section{References}

1. Sandhaus R. Lung disease of Alpha-1 Antitrypsin Deficiency. In: Wanner A, Sandhaus RA, eds. Alpha-1 Antitrypsin. Springer International Publishing: Switzerland. 2016. doi: https://doi.org/10.1007/978-3-319-23449-6_6

2. Stoller JK, Piliang M. Panniculitis in alpha-1 antitrypsin deficiency: a review. Clin Pulm Med. 2008;15(2):113-117. doi: https://doi.org/10.1097/CPM.0b013e3181672239

3. Matamala N, Lara B, Sáez R, et al. Novel genetic variants in alpha-1 antitrypsin deficiency cases carrying $S$ alleles and discordant genotype and serum levels. Eur Respir J. 2015;46(suppl 59). doi: https://doi.org/10.1183/13993003.congress-2015.PA4897

4. Banasik J. Diagnosing alpha 1-antitrypsin deficiency. Nurse Pract. 2001;26(1):58-62, 64, 67; quiz 68-69.

5. Steiner SJ, Gupta SK, Croffie JM, Fitzgerald JF. Serum levels of a1-antitrypsin predict phenotypic expression of the a1antitrypsin gene. Dig Dis Sci. 2003;48(9):1793-1796.

6. Hutchison DC. Alpha 1-antitrypsin deficiency in Europe: geographical distribution of Pi types S and Z. Respir Med. 1998;92(3):367-377.

doi: https://doi.org/10.1016/S0954-6111(98)90278-5

7. Stockley RA, Dirksen A, Stolk J. Alpha-1 antitrypsin deficiency: the European experience. COPD. 2013;10 (Suppl 1):50-53. doi: https://doi.org/10.3109/15412555.2013.765838

8. Lara B, Miravitlles M. Spanish registry of patients with alpha-1 antitrypsin deficiency; comparison of the characteristics of PISZ and PIZZ individuals. COPD. 2015;12 (Suppl 1):27-31. doi: https://doi.org/10.3109/15412555.2015.1021912

9. de Serres FJ. Worldwide racial and ethnic distribution of a1antitrypsin deficiency: summary of an analysis of published genetic epidemiologic surveys. Chest. 2002;122(5):1818-1829. doi: https://doi.org/10.1378/chest.122.5.1818

10. Turino GM, Barker AF, Brantly ML, et al. Clinical features of individuals with $\mathrm{PI}^{*} \mathrm{SZ}$ phenotype of alpha 1-antitrypsin deficiency. alpha 1-antitrypsin deficiency registry study group. Am J Respir Crit Care Med. 1996;154(6):1718-1725. doi: https://doi.org/10.1164/ajrccm.154.6.8970361

11. Green CE, Vayalapra S, Hampson JA, Mukherjee D, Stockley RA, Turner AM. PiSZ alpha-1 antitrypsin deficiency (AATD): pulmonary phenotype and prognosis relative to PiZZ AATD and PiMM COPD. Thorax. 2015;70:939-945 doi: https://doi.org/10.1136/thoraxjnl-2015-206906

12. Fregonese L, Stolk J, Frants RR, Veldhuisen B. Alpha-1 antitrypsin Null mutations and severity of emphysema. Respir Med. 2008;102(6):876-884.

doi: https://doi.org/10.1016/j.rmed.2008.01.009
13. DeMeo DL, Silverman EK. a1-antitrypsin deficiency. 2: Genetic aspects of a1-antitrypsin deficiency: phenotypes and genetic modifiers of emphysema risk. Thorax. 2004;59(3):259-264. doi: https://doi.org/10.1136/thx.2003.006502

14. Hutchison DCS. Natural history of alpha-1-protease inhibitor deficiency. Am J Med. 1988;84 (Suppl 6):3-12. doi: https://doi.org/10.1016/S0002-9343(88)80065-2

15. Campos MA, Alazemi S, Zhang G, Wanner A, Sandhaus RA. Effects of a disease management program in individuals with alpha-1 antitrypsin deficiency. COPD. 2009;6(1):31-40. doi: https://doi.org/10.1080/15412550802607410

16. Glickman ME, Rao SR, Schultz MR. False discovery rate control is a recommended alternative to Bonferroni-type adjustments in health studies. J Clin Epidemiol. 2014;67(8):850-857. doi: https://doi.org/10.1016/j.jclinepi.2014.03.012

17. Charlson ME, Pompei P, Ales KL, MacKenzie CR. A new method of classifying prognostic comorbidity in longitudinal studies: development and validation. J Chronic Dis. 1987;40(5):373-383. doi: https://doi.org/10.1016/0021-9681(87)90171-8

18. Alpha-1 Foundation. Big Fat Reference Guide. Alpha-1 Foundation website. https://www.alpha1.org/Alphas-FriendsFamily/Publications/Big-Fat-Reference-Guide Published 2005. Updated 2018. Accessed July 2018.

19. Häggblom J, Kettunen K, Karjalainen J, Heliövaara M, Jousilahti P, Saarelainen S. Prevalence of PI*Z and PI*S alleles of alpha1-antitrypsin deficiency in Finland. Eur Clin Respir J. 2015;2 (1):28829. doi: https://doi.org/10.3402/ecrj.v2.28829

20. De Serres F, Blanco I, Fernández-Bustillo E. Estimates of PI* S and $\mathrm{PI}^{*} \mathrm{Z}$ alpha-1 antitrypsin deficiency alleles prevalence in the Caribbean and North, Central and South America. Monaldi Arch Chest Dis. 2016;71(3).

doi: https://doi.org/10.4081/monaldi.2009.354

21. Piras B, Ferrarotti I, Lara B, et al. Clinical phenotypes of Italian and Spanish patients with alpha1-antitrypsin deficiency. Eur Respir J. 2013;42(1):54-64.

doi: https://doi.org/10.1183/09031936.00104712

22. Needham M, Stockley R. Exacerbations in a1-antitrypsin deficiency. Eur Respir J. 2005;25(6):992-1000. doi: https://doi.org/10.1183/09031936.05.00074704

23. Stone H, Pye A, Stockley RA. Disease associations in alpha-1antitrypsin deficiency. Respir Med. 2014;108(2):338-343. doi: https://doi.org/10.1016/j.rmed.2013.10.006

24. Dahl M, Tybjaerg-Hansen A, Sillesen H, Jensen G, Steffensen R, Nordestgaard BG. Blood pressure, risk of ischemic cerebrovascular and ischemic heart disease, and longevity in alpha(1)-antitrypsin deficiency: the Copenhagen City Heart Study. Circulation. 2003;107(5):747-752. doi: https://doi.org/10.1161/01.CIR.0000049642.20484.5D 
25. Needham M, Stockley R. a1-antitrypsin deficiency• 3: clinical manifestations and natural history. Thorax. 2004;59(5):441-445. doi: https://doi.org/10.1136/thx.2003.006510

26. McBride CM, Koehly LM, Sanderson SC, Kaphingst KA. The behavioral response to personalized genetic information: will genetic risk profiles motivate individuals and families to choose more healthful behaviors? Annu Rev Public Health. 2010;31:89103.

doi: https://doi.org/10.1146/annurev.publhealth.012809.103532

27. Carpenter MJ, Strange C, Jones Y, et al. Does genetic testing result in behavioral health change? Changes in smoking behavior following testing for alpha-1 antitrypsin deficiency. Ann Behav Med. 2007;33(1):22-28.

doi: https://doi.org/10.1207/s15324796abm3301_3

28. McBride CM, Bepler G, Lipkus IM, et al. Incorporating genetic susceptibility feedback into a smoking cessation program for African-American smokers with low income. Cancer Epidemiol Biomarkers Prev. 2002;11(6):521-528.

29. Chao S, Roberts JS, Marteau TM, Silliman R, Cupples LA, Green $\mathrm{RC}$. Health behavior changes after genetic risk assessment for Alzheimer disease: The REVEAL Study. Alzheimer Dis Assoc Disord. 2008;22(1):94-97.

doi: https://doi.org/10.1097/WAD.0b013e31815a9dcc

30. Marteau T, Senior V, Humphries SE, et al. Psychological impact of genetic testing for familial hypercholesterolemia within a previously aware population: a randomized controlled trial. Am J Med Genet A. 2004;128a(3):285-293.

doi: https://doi.org/10.1002/ajmg.a.30102

31. Perkins JT, Choate R, Mannino DM, Browning SR, Sandhaus RA. Benefits among patients with alpha- 1 antitrypsin deficiency enrolled in a disease management and prevention program. Chronic Obstr Pulm Dis. 2017;4(1):56-64. doi: https://doi.org/10.15326/jcopdf.4.1.2016.0161

32. Hogarth DK, Rachelefsky G. Screening and familial testing of patients for a1-antitrypsin deficiency. Chest. 2008;133(4):981988. doi: https://doi.org/10.1378/chest.07-1001 